\title{
Minsky: moeda, restrição de sobrevivência e hierarquia do sistema monetário globalizado *
}

\author{
Ernani Teixeira Torres Filho**
}

\begin{abstract}
Resumo
Hyman Minsky é, em geral, conhecido por sua teoria da instabilidade financeira. Na sua visão, as crises no sistema capitalista moderno têm origem endógena, por causa da tendência de empresas e bancos a adotarem um comportamento cada vez mais especulativo, na medida em que a estabilidade econômica se prolonga. Outros conceitos originais e igualmente relevantes desenvolvidos por Minsky são menos tratados pela literatura, inclusive pós-keynesiana. É o caso da "restrição de sobrevivência". Esse texto pretende cobrir essa lacuna, apresentando e discutindo a relevância da restrição de sobrevivência do ponto de vista da teoria da moeda e da conformação hierarquizada que o sistema monetário globalizado tomou a partir da Crise de 2008.
\end{abstract}

Palavras-chave: Teoria da Moeda, Minsky, Sistema Monetário, Sistema Monetário Internacional.

\begin{abstract}
Minsky on money, the survival constraint and the current hierarchy of the globalized monetary system

Hyman Minsky is well-known for his contributions to the theory of financial instability. He proposes that crises in the capitalist system have an endogenous origin since companies and banks adopt increasingly speculative behavior, the longer a period of economic stability lasts. However, other original and relevant concepts developed by Minsky, such as the 'survival constraint', are not as widely discussed in the literature. This study intends to cover this gap, presenting and discussing the relevance of the survival constraint to the theory of money and to the understanding of the hierarchy adopted by the globalized monetary system, after the 2008 crisis.
\end{abstract}

Keywords: Theory of Money, Minsky, Monetary Systems, International Monetary System.

JEL B5, E4, E5, F5, G2.

\section{Introdução}

As ideias de Hyman Minsky normalmente ganham destaque quando os sistemas financeiros são fortemente afetados por crises. Tem sido assim desde os anos 1980. Sua Hipótese da Instabilidade Financeira foi, por exemplo, largamente utilizada para explicar os motivos que levaram a economia americana - e a mundial - à Crise Financeira de 2008 (Minsky, 1992). Entretanto, há outros aspectos da sua obra que ainda são poucos conhecidos, como é o caso da "restrição de sobrevivência" ou survival constraint. Nesse cenário, esse texto tem por objetivo apresentar esse conceito para, em seguida, utilizá-lo para analisar a operação

\footnotetext{
* Artigo recebido em 31 de março de 2019 e aprovado em 20 de dezembro de 2019.

** Professor do Programa de Pós-Graduação em Economia Política Internacional (PEPI) da Universidade Federal do Rio de Janeiro (UFRJ), Rio de Janeiro, RJ, Brasil. E-mail: ernanit@hotmail.com. ORCID: http://orcid.org/0000-0001-9588-5769.
} 
hierarquizada dos sistemas monetários nacionais e do internacional, segundo a conformação que tomou a partir de $2008^{1}$.

Minsky buscou, dentro do pensamento pós-keynesiano, atribuir centralidade aos aspectos financeiros para o entendimento do comportamento dos agentes econômicos e das flutuações no nível de atividade. Isso o levou a apontar para a necessidade de se observar com atenção o papel desempenhado pelos fluxos de caixa. Desse ponto de vista, os agentes econômicos - sejam eles famílias, empresas ou bancos - deveriam ser vistos basicamente como unidades autônomas que precisam continuamente administrar sua restrição de sobrevivência (caixa) sob a pena de serem levados à extinção (falência) ou à penúria.

Para tanto, esses agentes contam, no primeiro momento, com o dinheiro proveniente de suas entradas correntes ${ }^{2}$. Se essa fonte for insuficiente, existe ainda a possibilidade de venderem seus ativos líquidos ou buscarem empréstimos junto a bancos ou ao mercado de capitais. A partir dessa perspectiva, a restrição de sobrevivência dá suporte à Hipótese da Instabilidade Financeira e à diferenciação minskyana das estratégias dos agentes econômicos com relação ao seu risco financeiro. Minsky sugeriu que as unidades econômicas fossem classificadas de acordo com três tipos de perfil de risco: as hedged, especulativas ou Ponzi.

No plano agregado, os sistemas econômicos modernos, por serem baseados em moeda fracionária, dispõem de mecanismos que podem automaticamente aumentar ou reduzir a disponibilidade global de moeda. Com isso, é possível se atender às flutuações na demanda agregada dos agentes por dinheiro, decorrentes de variações no nível da atividade e nos preços ou decorrentes de mudanças na composição dos portfólios de ativos dos detentores da riqueza. Esse mecanismo pode também ser usado como instrumento de disciplina limitando as opções financeiras dos agentes econômicos e reforçando suas restrições de sobrevivência. Essa visão minskyana se mostra útil para o entendimento da operação hierarquizada dos sistemas monetários modernos, nacionais e internacional. Com isso, abrem-se perspectivas inovadoras para o campo da Economia, mas também para áreas de conhecimento conexas, como, por exemplo, da Economia Política Internacional.

Diante desse cenário, esse texto está dividido em quatro seções, além dessa introdução e das conclusões. Na primeira, se apresenta uma breve resenha do debate entre a teoria clássica e a pós-keynesiana em torno ao tema da moeda. O objetivo é apontar as principais diferenças entre essas duas escolas, tomando por base as contribuições de Keynes, de modo a facilitar o entendimento das inovações introduzidas por Minsky. Desse ponto de vista, a moeda deve ser vista primordialmente como uma tecnologia social, que disciplina os diferentes agentes, introduzindo uma limitação a suas decisões e comportamentos: a survival constraint. Para Minsky, a restrição de sobrevivência é tão importante quanto a busca do lucro na determinação do comportamento das empresas (Minsky; Papadimitriou, 2004)

(1) O conceito de "restrição de sobrevivência" foi apresentado por Minsky em sua tese de doutorado de 1954 (Minsky; Papadimitriou, 2004).

(2) Dinheiro é utilizado nesse texto como sinônimo de moeda. 
A seção seguinte apresenta a interface entre a restrição de sobrevivência e a Hipótese da Instabilidade Financeira. A próxima seção desenvolve uma visão minskyana hierarquizada dos sistemas monetários nacionais modernos. A survival constraint é administrada por meio de um sistema complexo de mercados em que operam instrumentos de realocação e de flexibilização e disciplina. A última seção aplica essa visão analítica de Minsky ao atual sistema monetário internacional, de acordo com a configuração que tomou após a Crise de 2008. São incluídas, portanto, as mudanças que ocorreram, inclusive no relacionamento entre o banco central americano (Fed) e os outros cinco mais importantes bancos centrais do planeta.

\section{A moeda nas teorias econômicas clássica e keynesiana e a "restrição de sobrevivência" minskyana}

A moeda é um dos temas mais controversos da literatura econômica. Esse debate inclui desde os determinantes da sua origem, o tema da liquidez e a hierarquia das suas funções, até seu papel na determinação dos agregados econômicos, como a renda e o emprego. Essas divergências já se estendem por mais de dois séculos e envolvem posições por vezes inteiramente díspares.

No pensamento clássico (no sentido keynesiano do termo), a origem da moeda está associada à divisão do trabalho em uma economia marcada pelas trocas diretas (escambo). Nesse contexto, o dinheiro é tão somente uma mercadoria específica, que se destaca das demais pelas facilidades que oferece à operação das trocas. Apresenta vantagens pelas características intrínsecas que possui, tais como durabilidade e transferibilidade. Estas qualidades a tornam naturalmente mais atrativa para desempenhar o papel de meio de pagamento, ou seja, lhe atribuem uma condição diferenciada de liquidez. Isto, por exemplo, explicaria o uso de metais como moeda ao longo da história.

Essa versão da origem da moeda está presente na Riqueza das Nações de Adam Smith de 1776 (Smith, 2007) e continua sendo aceita até os dias de hoje, a despeito das inúmeras críticas formuladas por economistas, historiadores e antropólogos (Ingham, 2004). A partir desse ponto de partida, segue-se, para os autores filiados ao pensamento clássico, que a principal função da moeda é a de servir como meio de troca. É isso que lhe dá especificidade. Ser unidade de conta e reserva de valor seriam atributos de menor relevância.

Smith não parece ter admitido que mudanças na oferta de moeda pudessem ter impacto sobre o nível da atividade. Ele tratou a renda como se fosse determinada apenas por variáveis reais. Alterações no estoque de dinheiro influenciariam unicamente o nível de preços (Rockoff, 2013). Entretanto, outros quantitativistas como Hume (1777) e, posteriormente, Friedman (1973) apresentaram versões menos rígidas dessa mesma teoria, reconhecendo que variações na quantidade de dinheiro teriam efeito sobre a renda, apesar de limitadas ao curto prazo. No longo prazo, a moeda continuaria a ser neutra, já que todo o impacto de uma mudança na quantidade de dinheiro sobre as variáveis reais se dissiparia necessariamente em variações positivas ou negativas nos preços. 
Keynes se opôs frontalmente ao tratamento dado à moeda pela teoria clássica. Para ele, a principal limitação dessa visão estava exatamente em não atribuir ao dinheiro um papel ativo tanto no curto quanto no longo prazo. Ele concordou com historiadores e antropólogos de que não há evidências históricas de sociedades primitivas que tenham se organizado com base no escambo (Graeber, 2011; Martin, 2014). Em lugar da mitologia smithiana, adotou a perspectiva cartalista, que vê a moeda como uma criatura do Estado e não do mercado.

No Tratado da Moeda, publicado em 1930, Keynes afirmou que:

The State, therefore, comes in first of all as the authority of law which enforces the payment of the thing which corresponds to the name or description in the contracts. But it comes in doubly when, in addition, it claims the right to determine and declare what thing corresponds to the name, and to vary its declaration from time to time - when, that is to say, it claims the right to re-edit the dictionary. This right is claimed by all modem states and has been so claimed for some four thousand years at least (Keynes, 2011, p. 4).

O termo cartalismo foi cunhado por Knapp em 1924, mas a origem dessa visão é mais antiga e pode ser encontrada até mesmo em uma passagem do próprio Adam $\mathrm{Smith}^{3}$. De acordo com Knapp, o dinheiro utilizado em um determinado país foi, ao longo da história, fruto da decisão dos Estados de imporem aos agentes econômicos um tipo específico de ativo como meio de pagamento das obrigações fiscais. Segundo ele:

(...) all means by which a payment can be made to the State form part of the monetary system. On this basis it is not the issue, but the acceptation, as we call it, which is decisive. State acceptation delimits the monetary system. By the expression "State-acceptation" is to be understood only the acceptance at State pay offices where the State is the recipient (Knapp, 2003, p. 95).

É essa especificidade que garante à moeda uma vantagem de liquidez sobre eventuais substitutivos. Esse poder do Estado não deve ser confundido com o curso forçado da moeda estabelecido em lei (legal tender). Esse mecanismo reforça, mas não determina, o uso da moeda cartalista. Desse ponto de vista, a função básica da moeda é ser a unidade de conta.

O dinheiro não está, assim, limitado a nenhuma das formas concretas que foram adotadas ao longo da história: mercadoria (moeda metálica), papel (moeda fiduciária) e depósitos à vista (moeda bancária). Todos podem ser utilizados, desde que sejam aceitos pelo Estado como meios de pagamento de tributos.

Keynes atualizou o conceito de Knapp ao apontar que a maior liquidez da moeda está relacionada não só com sua capacidade de pagar impostos, mas também ao fato de ser a unidade que denomina e paga dívidas. No Tratado da Moeda, ponderou que:

(3) A prince, who should enact that a certain proportion of his taxes should be paid in a paper money of a certain kind, might thereby give a certain value to this paper money (Smith, 2007, p. 556). 
Money itself, namely that by delivery of which debt contracts and price contracts are discharged, and in the shape of which a store of general purchasing power is held, derives its character from its relationship to the money of account (...). Money proper in the full sense of the term can only exist in relation to a money of accoun (Keynes, 2011, p. 3).

Apesar de os instrumentos de dívida serem, em sua maioria, de natureza privada, esses contratos criam de forma generalizada volumosas obrigações de pagamento, por longos períodos de tempo, denominadas na moeda do Estado. É por esse motivo que Keynes fala não só do poder do Estado de fazer cumprir o "dicionário" (leis de curso forçado), mas também de reescrevê-lo, ou seja, de redefinir compulsoriamente aquilo que é aceito como moeda e, consequentemente, mudar unilateralmente a unidade de conta dos contratos, mesmo os já firmados.

Entretanto, a ruptura de Keynes com a economia clássica não se limitou às questões da origem e da hierarquia das funções da moeda. Seu propósito era mais amplo. Pretendia oferecer um paradigma totalmente novo para o pensamento econômico, que denominou de "economia monetária da produção" em oposição ao da visão clássica, que chamou de "economia de trocas reais". Nessa nova maneira de pensar, a moeda teria um papel central nas decisões de curto prazo - produção e emprego - mas também de longo prazo - ou seja, aquelas relacionadas às formas e ao ritmo de acumulação de capital. Em um texto de 1933, apontou que:

An economy, which uses money but uses it merely as a neutral link between transactions in real things and real assets and does not allow it to enter into motives and decisions, might be called - for want of a better name - a real-exchange economy. The theory which I desiderate would deal, in contradistinction to this, with an economy in which money plays a part of its own and affects motives and decisions and is, in short, one of the operative factors in the situation, so that the course of events cannot be predicted, either in the long period or in the short, without a knowledge of the behaviour of money between the first state and the last. And it is this which we ought to mean when we speak of a monetary economy (Keynes, 1933).

A partir da visão de Keynes sobre a moeda, Minsky introduziu a noção de "restrição de sobrevivência". Esse conceito se refere à obrigação à qual todos os agentes econômicos ${ }^{4}$ estão submetidos pelo Estado a realizarem pagamentos de impostos, dívidas e rendas contratadas na moeda emitida pelo poder público. Por esse motivo, essas unidades precisam, a todo o momento, comandar uma soma em dinheiro grande o suficiente para fazer frente a seus gastos. Caso contrário, estarão sujeitos a uma forte penalização, que pode chegar à penúria ou a falência. Para auxiliá-los na administração de seus fluxos de caixa, existem mercados e instituições especializadas no oferecimento de moeda, liquidez e na precificação de ativos. Segundo Minsky, a restrição de sobrevivência é um elemento tão importante nas estratégias e nas decisões das firmas quanto a maximização de lucro: "Business firms may be considered to be as interested in surviving as in maximizing profit" (Minsky; Papadimitriou, 2004, p. 152).

(4) À exceção do Banco Central, na moeda que emite. 
A obrigação de pagamento, portanto, é um elemento central em uma economia capitalista, pois é o mecanismo que sustenta o valor das dívidas (capital) e, consequentemente, o funcionamento de um sistema intrinsecamente baseado em relações financeiras. Segundo Minsky:

Survival conditions are an effective constraint upon the behavior of firms. (...). Survival conditions have been defined as requiring that total money expenses be less than or equal to total money receipts (ignoring whatever initial liquidity the firm possesses) for every time period from the initial position to the firm's horizon. The objective phenomenon related to the survival of a firm is its balance sheet structure (Minsky; Papadimitriou, 2004, p. 127).

O termo sobrevivência aparece nesse contexto com um duplo significado de urgência. Para as empresas, é o meio de evitar a falência. Para as famílias, é uma condição para garantir o provimento de suas necessidades mínimas de sustento (Nielson, 2019).

O conceito de restrição de sobrevivência reaparece em outros contextos da obra de Minsky. Um exemplo é quando ele trata do tema da regulação financeira (Torres e Martins, 2020). Desse ponto de vista, o mesmo Estado que criou a restrição de sobrevivência tem o poder de suspendê-la para determinadas empresas, quando essa limitação se torna, do seu ponto de vista, indesejada. Por esse motivo, os Estados Modernos suspenderam, na prática, a aplicação da restrição de sobrevivência aos grandes bancos comerciais ${ }^{5}$. Essa medida foi tomada como resposta aos impactos sistêmicos negativos que esse tipo de penalização, por meio de crises financeiras, gerava para o funcionamento da economia como um todo. Em contrapartida, os governos impuseram a essas mesmas instituições financeiras uma regulação que tem como principal propósito emular, a partir de normas legais de comportamento, o comportamento que, supostamente, os bancos deveriam adotar como política própria, caso ainda estivessem sujeitos à survival constraint:

In the absence of deposit insurance, a bank would be subject to depositor surveillance, and a run would occur if the bank lost the confidence of its depositors. With deposit insurance, the need for depositor surveillance is much diminished. This may mean that banks and other financial institutions will take more adventuresome positions. The central bank and the deposit insurance organization must therefore contain the exposure of banks. Regulation becomes the other side of the coin of deposit insurance (Minsky, 1986b, p. 16).

Minsky deixou de usar explicitamente o conceito de restrição de sobrevivência ao longo da sua vida. Entretanto, a preocupação com a centralidade das obrigações de pagamento esteve sempre presente nas suas discussões sobre liquidez, bancos, tipologias de risco, regulação e crise financeira. Esse talvez seja o motivo que levou à pouca presença da survival constraint na obra dos economistas que o sucederam.

(5) Nos últimos anos, essa isenção foi estendida a outros tipos de empresas consideradas sistemicamente importantes do ponto de vista financeiro (SIFI). 
Assim, por exemplo, L. Randall Wray, no mais importante livro que trata da revisão da obra de Minsky - Why Minsky Matters (Wray, 2016) - não menciona a existência da survival constraint, apesar de em várias passagens se referir ao tema, quando fala da existência de limitações de liquidez aos bancos (liquidity constraint) ou de uma disciplina de mercado (market discipline). O mesmo comportamento pode ser encontrado em outros autores como Bell (2001), Ingham (2004) e Kelton (2020), a despeito da relevância das ideias de Minsky em suas obras.

Entretanto, há um conjunto formado por outros autores pós-keynesianos, que buscaram nos últimos anos recuperar a importância da restrição de sobrevivência. Entre eles, destacamse Perry Mehrling e Daniel Nielson. Mehrling, em artigo publicado em 1999, afirmou que: "In the logic of finance, the most basic element of the economy is cash flow and the most basic constraint on the behavior of every economic agent is the "survival constraint" which requires that cash outflow not exceed cash inflow" (Mehrling, 1999, p. 139). Esse tema perpassa suas publicações desde então, inclusive em seu livro de 2011, The New Lombard Street. (Mehrling, 2011). Mais recentemente, Nielson publicou um livro, denominado "Minsky" (Nielson, 2019) em que faz um amplo apanhado da obra desse autor e atribui ao conceito de restrição de sobrevivência, uma posição central em seu pensamento.

\section{0 sistema monetário e financeiro e a hipótese da instabilidade financeira}

Graças à existência de mercados financeiros muito ativos e líquidos, as empresas e as famílias podem, no mundo moderno, adotar estratégias financeiras que permitem, sua convivência rotineira com uma forte restrição de sobrevivência. Conseguem, assim, operar normalmente com níveis reduzidos de "colchões de segurança" (cushions of safety) $)^{6}$. Essa situação acontece porque as unidades econômicas:

(...) often make payment commitments without having the cash on hand. Almost always, the expectation is that the cash flow from operations will be large enough to cover the commitment. However, if operations do not generate a sufficiently large cash flow, then the survival of the unit - or at least the avoidance of embarrassment - requires that the unit be able to borrow or sell assets to obtain the necessary cash. The extent to which savings intermediaries can be liquid, and to which firms can make commitments in advance of funding, depends upon the scope and strength of money market intermediation. The money market enables organizations to be safely illiquid - provided they have assets, which are eligible for this market. The basic raw material for the money market is the existence of pools of excess of liquidity (Minsky, 1967, p. 33).

(6) Os "colchões de segurança" (cushions of safety), de acordo com Wray (2017) podem ser de três tipos: a) o diferencial entre a receita futura esperada com algum grau de certeza e os compromissos assumidos ou projetados para o mesmo período, é o "colchão de fluxo de caixa" (cash-flow cushion); b) as reservas líquidas acumuladas pela unidade, ou seja, o "colchão de liquidez" (liquidity cushion), e c) a solidez do balanço da unidade, ou seja, a capacidade de uma empresa ou família de tomar crédito sem oferecer garantias (balance-sheet cushion). 
A redução nas margens de segurança reflete o fato de que, na medida que o sistema econômico se mantem estabilizado, a própria concorrência e a busca do lucro criam condições para que sejam, cada vez mais, concedidos empréstimos, em que se prevê que as receitas operacionais líquidas do serão insuficientes para atender ao pagamento da dívida contraída. Nesses casos, já se espera de antemão o refinanciamento desses créditos antes do fim do prazo contratado. Entretanto, essa racionalidade amplia o nível de fragilidade financeira na medida em que empresas e seus bancos ficarão sujeitos ao risco relacionado às condições de preço e prazo prevalecentes no mercado financeiro no momento em que essa renegociação se der no futuro. Essas unidades financeiramente mais frágeis são chamadas por Minsky de especulativas. Elas se diferenciam das robustas ou hedged exatamente pelo fato de essas últimas não carregarem esse tipo de risco financeiro em seus balanços

Para Minsky, o comportamento especulativo tende, com o tempo, a se generalizar na economia. Surgem, inclusive, unidades nas quais o descompasso entre as vendas e a estrutura de financiamento é tão elevado que as obriga a aumentar suas dívidas continuamente para manterem em dia o pagamento de seus débitos. Nestes casos, nem mesmo os juros conseguem mais ser integralmente pagos com as receitas líquidas correntes. Com isso, a solvência desses agentes estará a todo momento ameaçada pelas mudanças nas condições de liquidez do mercado financeiro e pela percepção de risco dos investidores. Esse grupo de empresas muito especulativas foi chamado por Minsky de Ponzi.

É por esse motivo que Wray (2011) afirma que "a estabilidade é instabilizante". É muito baixa a possibilidade de uma unidade hedged romper sua restrição de sobrevivência, até mesmo em uma situação de estresse financeiro. No entanto, para os agentes especulativos para não falar dos Ponzi - trata-se de um risco real. Assim, na medida em que se amplia a proporção de unidades financeiramente frágeis, maior será a probabilidade de uma redução inesperada no nível de atividade se transformar em uma crise de grave proporções. A fragilização financeira faz com que as unidades econômicas deixem de ser capazes de absorver choques para se tornarem seus amplificadores para o resto da economia. Essa teoria é conhecida como a Hipótese da Instabilidade Financeira (Minsky, 1992).

A expansão de unidades econômicas especulativas e Ponzi está, assim, diretamente relacionada à operação rotineira e eficiente dos mercados de liquidez e de crédito. Esse aspecto nos leva ao segundo conceito importante na visão minskyana associada à restrição de sobrevivência: a presença dentro do sistema monetário moderno de instrumentos que permitem que os limites individuais e globais impostos pelo survival constraint sejam administráveis. Para tanto, existem dois conjuntos de mecanismos diferentes, os de realocação e os de disciplina e flexibilização.

Os instrumentos de realocação, para poderem ser acionados, requerem a acumulação prévia de dinheiro pelos agentes. O mais básico deles é o que foi chamado por Keynes, na "Teoria Geral", de motivo precaucional de demanda de moeda. Para ele, unidades econômicas têm um desejo de "security as to the future cash equivalent of a certain proportion of total 
resources" (Keynes, 2007, p. 108). Nesse caso, os agentes econômicos mantêm saldos monetários inativos com o propósito de atender a demandas imprevistas de dinheiro, ou seja, para poderem equilibrar seu fluxo de caixa em uma situação inesperada e, com isso, evitar que possam ser expostos à restrição da sobrevivência.

Entretanto, nas economias modernas, o uso do dinheiro para fins precaucionais foi, há muito, substituído por alternativas mais eficientes. Há ativos financeiros muito líquidos, negociados em mercados organizados, que permitem que os agentes consigam atender situações de escassez de caixa e que, além disso, obtenham rendimentos. É o caso, por exemplo, dos títulos públicos, que podem ser facilmente vendidos em operações compromissadas. ${ }^{7}$ Outra possibilidade é a tomada de empréstimos junto aos "reservatórios de dinheiro" (cash pools) detidos por grandes empresas ${ }^{8}$ ou por instituições financeiras especializadas ${ }^{9}$. Essas operações são reguladas pelas flutuações na estrutura a termo da taxa de juros.

Os mecanismos de disciplina e flexibilização são distintos dos de realocação, apesar de cumprirem a mesma função de adicionar novas entradas ao fluxo de caixa dos agentes econômicos. A diferença, nesse caso, está no impacto que possuem sobre a disponibilidade de moeda para a economia como um todo. Keynes havia alertado, no debate que se seguiu à publicação da Teoria Geral em 1937, que há momentos em que a maior demanda de moeda dos agentes só poderá ser plenamente atendida através da mobilização dos mecanismos de flexibilização. Segundo ele: "the transition from a lower to a higher scale of activity involves an increased demand for liquid resources which cannot be met without a rise in the rate of interest, unless the banks are ready to lend more cash" (Keynes, 1937a, p. 668).

A preocupação de Keynes nesse trecho era mostrar que a expansão da oferta de moeda pelos bancos - e, portanto, a flexibilização da "restrição de sobrevivência" para o conjunto dos demais agentes econômicos - é um aspecto central para que a ampliação do nível de atividade possa se efetivar. Caso contrário, diante de uma disponibilidade inflexível de moeda, as empresas, mesmo quando animadas por um forte animal spirit, se veriam tolhidas pelos limites impostos pela disciplina da disponibilidade global de moeda

A flexibilização e a disciplina nos sistemas monetários são operadas em dois níveis. No primeiro, está o conjunto de bancos comerciais. Toda vez que uma dessas instituições concede um empréstimo a uma família, empresa, órgão de governo ou instituição financeira não-monetária ${ }^{10}$ há a criação de um depósito à vista (moeda). Em compensação, sempre que

(7) Uma operação compromissada compreende a venda de um título de dívida, normalmente de emissão pública, por prazo curto - geralmente de um dia - por um preço inferior a seu valor de face com o direito de recompra pelo vendedor por um valor superior ao que foi pago, normalmente referente à taxa de juros de mercado pelo período da operação.

(8) Um exemplo de cash pool é a empresa americana Apple que nas informações que prestou ao mercado no final de 2018, informou que detinha em novembro daquele ano o montante de US $\$ 237,1$ bilhões em caixa.

(9) Os Money Market Funds americanos são fundos que oferecem a seus clientes aplicações com liquidez instantânea, remuneração na forma de juros e, em alguns casos, garantia de principal, como se fossem depósitos à vista não-remunerados e aplicam seus recursos em títulos privados de baixo risco e, principalmente, na dívida pública.

(10) Instituição financeira que não os bancos que emitem depósito à vista. 
algum desses clientes paga uma dívida ou empresta dinheiro a um banco emissor de depósitos à vista, há uma destruição de moeda. Assim, o resultado líquido dessas operações afeta rotineiramente a quantidade de moeda disponível na economia e, consequentemente, amplia ou reduz a restrição global à que esses agentes econômicos estão sujeitos.

Uma forma simples de as unidades econômicas acessarem os mecanismos de flexibilização e disciplina é disporem de linhas de crédito pré-aprovadas de curto prazo junto a bancos comerciais, que possam ser desembolsadas de forma automática - como, por exemplo, os chamados "cheques especiais". Entretanto, isso requer que a empresa seja considerada de baixo risco ou que possa oferecer ativos dessa mesma qualidade como garantia.

Esses bancos, por sua vez, ao aumentarem suas operações de crédito com seus clientes, também comprometem seu próprio fluxo de caixa, que é operado por meio de um mecanismo monetário exclusivo dessas instituições: os saldos das contas de reservas que mantêm junto ao banco central. Na prática, uma eventual escassez de reservas por parte de um banco pode ser facilmente compensada por um empréstimo interbancário, já que a redução nos depósitos de uma instituição necessariamente significa um aumento no saldo de outra.

Entretanto, há situações em que pode haver um comprometimento da liquidez do sistema bancário como um todo. Nesse caso, para evitar que a restrição de sobrevivência das instituições comerciais comprometa a expansão do restante dos agentes econômicos, é necessário que o banco central não introduza mais disciplina no sistema, se opondo ao aumento do volume global de reservas desejado pelos bancos, por meio de um aumento da taxa de juros de curto prazo.

\section{A hierarquia de um sistema monetário nacional típico}

Os mecanismos de flexibilização e disciplina permitem identificar a existência de uma hierarquia no interior dos sistemas monetários nacionais (SMN). As principais exceções a esse tipo de conformação seriam os EUA, porque emitem a moeda internacional hegemônica, e as economias que não usam uma moeda nacional, preferindo utilizar a de um país estrangeiro ${ }^{11}$. O regime cambial - flexível ou fixo - e o de conversibilidade - ampla ou restrita - que cada país adota não afetam a conformação de um SMN, mas, apenas, sua operação.

O exemplo apresentado na Figura 1 se refere a um SMN dentro do atual ambiente internacional globalizado (Torres, 2014). Trata-se de um sistema composto por quatro níveis. O piso inferior (N1) é formado pelos agentes não emissores de moeda (ANE): famílias,

(11) Nessas economias o SMN tem apenas três níveis. No caso dos EUA, isso se dá por que sua moeda é hegemônica internacionalmente e por isso o país não está sujeito a um limite de sobrevivência determinado externamente. No caso de países que adotam uma moeda internacional no lugar de uma própria, como é o caso de alguns países latino-americanos de menor porte com relação ao dólar - Equador, Panamá e El Salvador - o banco central local perde o poder de atuar como um nível autônomo de flexibilização interno e passa a integrar o nível 2 junto com os bancos comerciais, operando como um "banco atacadista". Esse tema, no entanto, transcende ao objetivo desse artigo (Ver Torres, 2019a). 
empresas, entidades públicas, exceto o banco central, e instituições financeiras, à exceção dos bancos comerciais.

Figura 1

Sistema monetário nacional típico, hierarquizado do ponto de vista minskyano

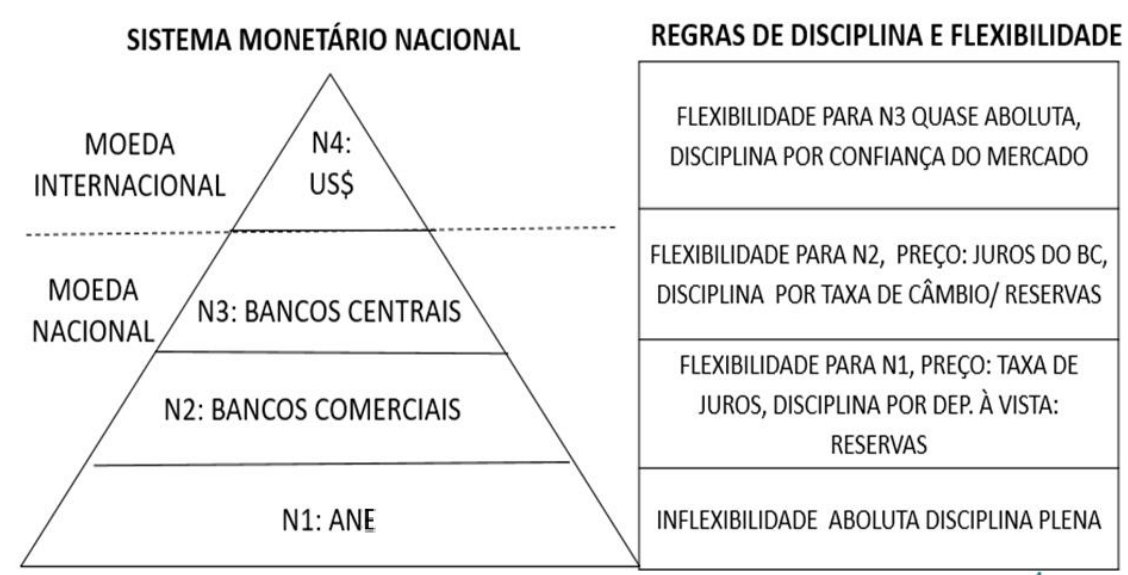

Fonte: Elaboração do autor.

Os ANE têm em comum o fato de não serem capazes de emitir moeda por seus próprios meios e terem seu fluxo de caixa corrente como fonte básica de entradas de dinheiro. Eles podem, além disso, mobilizar, no curto prazo, os ativos líquidos que possuam, sempre que, em um dado momento, suas receitas correntes não forem suficientes para financiar seus gastos. Entretanto, a venda de ativos tende normalmente a ser uma forma limitada de obtenção de dinheiro. Como alternativa, podem ainda contratar dívidas com outros ANE. A mobilização desses mecanismos dependerá da liquidez dos mercados e da situação de risco de cada tomador. Todos esses mecanismos de realocação não afetam o total de dinheiro disponibilizado para o conjunto dos ANE. Eles apenas realocam dentro desse mesmo grupo o volume de moeda já detido por esses agentes.

No entanto, se essa maior demanda por moeda esbarrar no limite das disponibilidades correntes de liquidez do conjunto das ANE, esses agentes ainda poderão recorrer aos bancos comerciais, que formam o segundo nível da hierarquia do sistema monetário (N2). A especificidade dessas instituições financeiras é serem capazes, ademais de operarem como mecanismos de realocação, de atender às necessidades de caixa dos agentes não emissores, mediante a criação de depósitos à vista. Trata-se de um mecanismo endógeno de flexibilidade, mas também de disciplina, para o conjunto dos ANE, que lhes permite alcançar um nível de gastos superior ao que atingiriam, caso tivessem que limitar seus dispêndios à quantidade de moeda já existente.

Essa descrição do comportamento das unidades econômicas no acesso aos mecanismos de realocação e de flexibilização e disciplina não corresponde, no entanto, ao real 
funcionamento do mercado. Seu propósito é meramente analítico: separar a circulação do dinheiro já detido pelos ANE do mecanismo de flexibilização e disciplina associado à criação de moeda pelos bancos.

Na prática, a ordem de prioridade de mobilização de liquidez pelos ANE é diferente. Se suas receitas correntes não forem capazes - ou já se espera que não venham a ser capazes de atender às despesas, seu passo seguinte é tomar empréstimos junto a bancos ou a outras ANE. Os demais instrumentos de realocação são mobilizados apenas em situações emergenciais. O mecanismo de flexibilidade dos bancos comerciais é, assim, acionado rotineiramente, expandindo ou contraindo automaticamente a oferta de moeda, conforme a demanda global dos agentes não emissores.

Transações envolvendo dinheiro ${ }^{12}$ entre agentes não monetários e entre estes e os bancos comerciais se ajustam a partir da existência de um mesmo preço, a taxa de juros. A todo momento, existem unidades que precisam obter uma quantidade adicional de moeda para suprir um desequilíbrio corrente de seu fluxo de caixa. A urgência dessa demanda os obriga a aceitar o preço que o mercado estiver praticando por esse serviço de aluguel de moeda - taxa de juros - ou para a compra de um ativo - taxa de desconto.

Há também unidades que estão interessadas em deter uma quantia maior de dinheiro, mas sem tanta urgência para gastá-lo. Sua demanda decorre de uma previsão de maiores de gastos no futuro. Essa classe de atores pode, portanto, postergar a tomada de novos recursos, dependendo do preço de mercado. A taxa de juros para todos esses ANE é, assim, o custo que precisam pagar para adiarem uma obrigação de pagamento ou eventualmente aumentarem seu comando sobre um volume maior de recursos líquidos.

Na posição oposta, estão as unidades com excedente de caixa e os bancos comerciais. Os cash pools - tendo em vista a taxa de juros de mercado, seu fluxo de caixa esperado e suas expectativas sobre o futuro - podem decidir reduzir suas disponibilidades de dinheiro e com isso ajudar a solucionar o déficit de caixa de outros agentes. Normalmente, a elasticidade da oferta desses atores a uma redução da taxa de juros é baixa.

Além disso, estão presentes também os bancos comerciais, mas com uma atuação diferente. Eles também podem atuar como intermediários dos detentores de excedentes de caixa. Entretanto, adicionalmente, podem expandir seu passivo monetário - depósitos à vista e, com isso, flexibilizar, do ponto de vista coletivo, a restrição da sobrevivência do conjunto dos ANE. O resultado da interação entre esses três conjuntos de atores - cash pools, bancos comerciais e ANE demandantes de caixa - fixa a estrutura a termo da taxa de juros, a partir da taxa básica imposta pelo banco central.

(12) O termo dinheiro é usado nesse texto como sinônimo de moeda. 
Os bancos comerciais também estão sujeitos a uma survival constraint só que operada através de um meio de pagamento exclusivo deles - os depósitos ${ }^{13}$ que precisam manter junto ao banco central - e da obrigação de garantirem a conversibilidade ao par de seus depósitos à vista em papel-moeda (Mehrling, 2013). Para lidar com essa limitação, essas instituições contam com seus próprios cash pools: os saldos em excesso que algumas dessas instituições detém junto ao banco central. Podem também vender ativos líquidos e, em casos extremos, recorrer diretamente ao banco central.

Se o conjunto dos bancos comerciais demandar uma expansão do volume total de reservas, cabe ao o banco central gerir a flexibilização desse limite e, por esse motivo, a autoridade monetária responde pelo terceiro nível do sistema monetário minskyano (N3). Desde os anos 1980, a atuação dos bancos centrais tem se pautado pela fixação da taxa de juros de um dia, sendo a quantidade de reservas uma consequência desse processo (Mehrling, 2011). Os bancos comerciais têm capacidade de autonomamente aumentar seus depósitos na autoridade monetária, mediante o uso de instrumentos como, por exemplo, a venda de um volume maior de títulos públicos. A autoridade monetária, caso queira se opor a essa tendência do mercado, poderá por conta própria promover a disciplina no SMN por meio de um aumento da taxa básica de juros, aumentando o custo dos mecanismos de liquidez acessíveis aos bancos comerciais. Entretanto, o resultado geral dessas operações sobre o volume de reservas só será conhecido ex-post.

A autoridade monetária não está sujeita a uma survival constraint na unidade de conta que emite e, por isso, pode criar ou destruir reservas de forma praticamente ilimitada. Entretanto, os demais provedores de recursos monetários, sejam eles ANE com excesso de caixa ou bancos comerciais, estão sujeitos a uma preferência pela liquidez. Assim, nos momentos de stress nos mercados, os cash pools e os bancos comerciais tendem a reduzir fortemente sua oferta de dinheiro, promovendo uma maior disciplina de caixa para os demais agentes. Por esse motivo, a presença de um banco central é essencial para a estabilidade de uma economia capitalista moderna.

Finalmente, em um mundo globalizado moderno, os principais ANE, os bancos nacionais mais importantes e os bancos centrais das economias mais importantes não operam em ambientes autárquicos. Pelo contrário, realizam em geral transações simultaneamente na moeda nacional e na internacional (De Conti et al., 2013). Assim, na prática, estão também sujeitos, diretamente e por força do sistema monetário de cada país, a um fluxo de caixa e, portanto, a uma restrição de sobrevivência na moeda americana.

Um exemplo da relevância da survival constraint na moeda internacional pode ser encontrado na crise de liquidez em dólares que se abateu sobre os grandes bancos europeus após a crise de 2008. Esse problema levou o Federal Reserve (Fed) a recriar a linhas de swaps de moedas com o Banco Central Europeu, para facilitar o acesso dos bancos sob sua supervisão

(13) Atualmente, por força das inovações regulatórias introduzidas pelos Acordos de Basiléia em todo o mundo, os bancos comerciais também estão sujeitos a limites no valor dos ativos que podem carregar dependendo do risco a eles atribuídos e do tamanho capital próprio da instituição. 
aos mecanismos de auxílio à liquidez oferecidos pelo banco central dos EUA (Tooze, 2018; Helleiner, 2014).

O dólar é uma moeda internacional que tem características fiduciárias, ou seja, seu emissor, o Fed, não está sujeito a nenhuma restrição de sobrevivência ${ }^{14}$. Entretanto, a situação dos demais países é radicalmente diferente. Todos estão obrigados a respeitar uma limitação imposta pela disponibilidade que tenham da moeda americana. Nas economias integradas ao sistema financeiro globalizado e que adotam a conversibilidade da sua conta de capital, essa survival constraint externa é operada através de um preço específico, a taxa de câmbio,

Esse mecanismo de disciplina, operado pelo mercado financeiro internacional, limita a capacidade de as autoridades monetárias nacionais, exceto dos EUA, flexibilizarem de forma irrestrita a atuação de seus bancos comerciais e de seus mercados na moeda local. Esse privilégio está, na prática, subordinado ao fluxo de caixa do país em moeda estrangeira, em termos correntes e esperados. Assim, por exemplo, em uma situação de escassez de divisas, o banco central, além de promover uma desvalorização cambial, pode precisar subir a taxa de juros - e aumentar a restrição de sobrevivência doméstica - de modo a obrigar os ANE do seu país a reduzir sua demanda corrente por moeda estrangeira ou a vender seus estoques de divisas no mercado interno.

O fluxo de caixa em dólares de uma nação financeiramente integrada ao sistema internacional é formado por um conjunto amplo de operações rotineiras e pulverizadas entre múltiplos agentes. Existem, por exemplo, as transações comerciais que são fechadas diretamente entre ANE locais e estrangeiros. Há também as operações financeiras em moeda estrangeira entre, de um lado, ANE e bancos comerciais nacionais e, de outro, financiadores no exterior.

Os bancos comerciais locais têm vantagens na captação externa sobre os ANE. Em geral, conseguem obter empréstimos em melhores condições por apresentarem um risco menor. Por serem emissores de depósito à vista na moeda local, estão sujeitos a uma regulação mais estrita e, de modo muitas vezes implícito, a um resgate do governo nacional em uma situação de crise. $\mathrm{O}$ Tesouro Nacional é também outro ator diferenciado na tomada de recursos externos por causa de seu porte elevado e pelo fato de ser, em geral, o principal emissor da dívida externa do país, quando não pelo volume, pelo fato de gerar a taxa de juros internacional que norteará as emissões dos demais agentes nacionais. O risco dos títulos do soberano determina normalmente o piso dos juros dos demais emissores de dívida externa estabelecidos no mesmo país.

Normalmente, os fluxos administrados pelos bancos comerciais e pelos ANE não se equilibram. Por esse motivo, os bancos centrais atuam rotineiramente nos mercados de câmbio

(14) O banco central americano não tem mais a obrigação de converter dólares em ouro a uma taxa pré-definida, como no padrão ouro do século XIX ou no sistema de Bretton Woods, no pós- $2^{\mathrm{a}}$ Guerra. 
de modo a oferecer ou adquirir moeda estrangeira ${ }^{15}$ tendo em vista a manutenção de taxas de câmbio fixas ou de bandas, no caso de o regime de câmbio ser flutuante. As autoridades monetárias contam, para isso, com o uso de suas reservas internacionais ou a venda de seus ativos internacionais.

Se esses mecanismos de liquidez externa são levados à exaustão ou houver uma concentração de gastos do país em moeda estrangeira, a saída para o banco central - geralmente por meio do Tesouro Nacional - para lidar com a survival constraint cambial é recorrer a empréstimos no exterior. As instituições ofertantes desses recursos podem ser privadas, de governos de outros países ou ainda multilaterais.

Todas as transações com o exterior se processam no interior do sistema monetário denominado em dólar. Apenas aquelas que envolvem a troca entre a moeda estrangeira e a nacional têm uma de suas pontas no mercado financeiro doméstico.

Na prática, os bancos centrais não precisam usar suas reservas internacionais para gerir o dia-a-dia do seu mercado de câmbio. Esse lugar é ocupado pelas captações de recursos feitas junto ao mercado privado de dólares, envolvendo principalmente o mercado financeiro americano e o Euromercado. Essa é a fonte primária de flexibilidade do sistema monetário internacional. Segundo Mehrling: "In effect, deficit countries typically settle daily not with owned reserves but rather with borrowed reserves, reserves borrowed either directly or indirectly from surplus countries in the private international money market. In this way short term capital flows facilitate international commerce, both gross and net, on both capital and trade account" (Mehrling, 2015, p. 1).

No caso do banco central americano, a situação é diferente. Não há diferenças entre seu sistema monetário nacional e o internacional. Existe um único mercado em que agentes nacionais e estrangeiros realizam operações financeiras entre si sem que haja fronteiras cambiais. Cada Sistema Monetário Nacional funciona como se fosse uma unidade especial de ANE do sistema monetário americano, composta por diferentes agentes domésticos que compartilham uma restrição de sobrevivência externa comum, ou seja, uma especificidade de risco, o de conversibilidade.

Esse esquema analítico minskyano foi ilustrado por meio da Figura 1. Na parte esquerda, na forma de um triângulo, há uma ilustração da hierarquia de um sistema monetário nacional em que está identificada a relevância, conforme o piso mais elevado que ocupa, de cada grupo de instituições conforme sua capacidade de flexibilização. No lado direito, está a qualificação de cada grupo em termos de disciplina, de flexibilidade e dos preços responsáveis por seu ajustamento.

(15) No Brasil, essa intervenção do Banco Central na taxa de câmbio é operada primordialmente através do mercado doméstico de derivativos de câmbio. 
Ernani Teixeira Torres Filho

\section{0 sistema monetário internacional dolarizado pós-2008}

Desde 1945, o sistema monetário internacional tem o dólar americano como moeda dominante (Torres, 2018). Assim, o núcleo central do sistema monetário internacional (SMI) é composto pelos níveis 1 a 3 do sistema monetário norte-americano, conforme exemplificado na Figura 1. No imediato pós-guerra, foram os ANE e os bancos dos EUA os principais veículos responsáveis pelo provimento de liquidez na moeda internacional para o resto do mundo. O governo americano teve um papel central nesse período de dollar shortage, uma vez que o superávit estrutural do seu setor privado com o exterior era compensado por meio de doações e gastos militares do governo dos EUA no resto do mundo (Block, 1977).

Durante a vigência do Acordo de Bretton Woods, seria necessário, ao menos do ponto de vista formal, agregar-se ao núcleo básico do sistema monetário americano um quarto nível, que seria integrado pelo mercado de ouro e por seu preço em dólares que, pelos termos do acordo, era fixo em US\$35,00 por onça. As agências multilaterais, como o Fundo Monetário Internacional e o Banco Mundial, seriam um tipo especial de ANE, já que não eram instituições com poder de flexibilizar autonomamente as restrições de sobrevivência na moeda americana de seus clientes - os governos dos países membros.

O mundo globalizado, que se seguiu à década de 1980, introduziu mudanças nesse esquema. A inovação mais importante para o poder americano foi, sem dúvida, o fim da obrigação de converter dólares em ouro. Com isso, a restrição de sobrevivência sobre o banco central americano - o nível 4 da Figura 1 - simplesmente deixou de existir. Em seu lugar, surgiu uma forma mais difusa de restrição de sobrevivência, associada ao poder dos cash pools públicos e privados em dólar. Os titulares desses recursos, ao final dos anos 1970, chegaram a ameaçar com a redução de seus estoques de riqueza na unidade de conta americana, caso os EUA continuassem a manter suas taxas de juros abaixo da inflação. Essa situação foi descrita por Helleiner:

In 1978-79, there was a crisis of confidence in the dollar (...). With no sign that the United States was going to reduce its growing external deficit and curb domestic inflation, foreigners began to lose confidence in the dollar. Saudi Arabia began to sell its dollar reserves and warned of an oil price increase if the dollar's depreciation continued. West European governments signaled their dissatisfaction with U.S. unilateralism by beginning negotiations that led to creation of the European Monetary System (EMS) in March 1979 (...). [The German Chanceller expressed] his frustration with U.S. economic policy and his "diminishing confidence in American leadership." Most important, there was enormous flight from the dollar in the increasingly powerful global financial markets. With the dollar entering a free fall, the United States suddenly faced the most severe external constraint on its policy autonomy in the postwar period (Helleiner, 1994, p. 131-132).

Outras transformações operaram no sentido de garantir maior poder ao capital financeiro privado para: administrar a liquidez e os ajustes dos participantes; integrar os países 
ao mercado financeiro internacional por meio da abertura das contas de capital; e promover a criação de mercados dolarizados offshore, a exemplo do euromercado.

O sistema globalizado produziu uma sucessão de crises na periferia do sistema, que se estenderam por quase duas décadas (1981-2001). Inicialmente os países latino-americanos foram muito afetados e ficaram à margem do sistema global por mais de uma década. Posteriormente, se seguiram os países do antigo bloco socialista e finalmente os do Sudeste da Ásia. Essa limitação só foi superada depois da virada do milênio na medida em que os principais países emergentes conseguiram acumular volumosas reservas internacionais, como contrapartida aos elevados déficits externos dos Estados Unidos. O fortalecimento desses mecanismos de realocação deu mais estabilidade à inserção internacional dessas economias.

As respostas americanas à crise internacional de 2008 inauguraram um novo perfil na hierarquia internacional do sistema dólar. Até então, o Fed atuava basicamente gerenciando a liquidez no mercado americano, através de operações compromissadas com títulos do Tesouro do EUA, e os bancos e os dealers se encarregavam de ajustar os demais mercados através de operações de arbitragem. Essas ações eram suficientes para mover não só o mercado monetário em dólares nos Estados Unidos, mas também no resto do mundo (Tooze, 2018).

O euromercado tem uma grande importância na operação dos mecanismos de liquidez em dólares fora dos Estados Unidos. Mesmo assim, deve ser entendido, do ponto de vista da hierarquia dos mecanismos de flexibilização monetária, como uma extensão para o exterior no caso para a Europa - do mercado monetário americano. Na prática, os depósitos em dólares no euromercado não refletem entradas e saídas de dólares dos Estados Unidos. Como afirmam Stigum e Crecenzi (2007, p. 211): "The first important point to make about Eurodollars is that regardless of where they are deposited - London, Singapore, Tokyo, or Brazil - they never leave the United States. Also, they never leave the United States regardless of where they are lent".

Assim, por exemplo, os depósitos à vista dolarizados em Londres são espelhos de depósitos que o banco emissor na Inglaterra detém em um banco em Nova Iorque. As reservas do sistema eurodólar são, por sua vez, depósitos em instituições que têm acesso aos mecanismos de liquidez do Federal Reserve. Para não ser obrigado a depender dessa relação indireta com a autoridade monetária americana, o euromercado opera de modo a "casar" (match) os prazos de suas operações ativas e passivas, usando operações a futuro. Segundo Mehrling, "matched book is the name of the game [in the Eurodollar market], and matched book in dollars" (Mehrling, 2015, p. 8).

Entretanto, por causa da Crise de 2008, toda a engrenagem nacional e internacional associada à liquidez da moeda americana simplesmente deixou de operar satisfatoriamente. $\mathrm{O}$ banco central americano se viu então obrigado a atuar de forma inovadora, utilizando-se até mesmo de dívida privada como instrumento de operações compromissadas e abrindo seu sistema de contas reserva a outros agentes, que não apenas aos bancos comerciais sediados nos Estados Unidos. 
Naquela oportunidade, o pragmatismo do Fed parece ter seguido à risca a recomendação que Minsky já havia feito em 1967. Para esse autor, a atuação dos bancos centrais em momentos de crise, para ter sucesso, não poderia seguir princípios préestabelecidos. Pelo contrário, teria que ser flexível de modo que a autoridade monetária viesse a adquirir "any type of asset it feels is necessary to avoid instability is a major requirement for the successful operation of a complex financial system. The central bank must follow, and in crisis ratify, what has taken place in the market. Only in times of stagnation or tranquillity can the economy afford a central bank that stands on principles" (Minsky, 1967, p. 54-55).

Dentre as mudanças mais importantes que foram introduzidas a partir de 2008 estão a obrigação de bancos de investimento e outras instituições financeiras relevantes dos Estados Unidos se reportarem ao Fed, ao mesmo tempo em que passavam a deter contas de reservas na instituição. Outra novidade foi a ampliação do portfólio de ativos utilizado pelo banco central americano para realizar operações compromissadas ( repo), que passou a incluir, além de títulos de dívida do tesouro americano, bonds privados emitidos por empresas, relacionadas ou não com o governo. As operações de liquidez deixaram de ser efetuadas exclusivamente com títulos públicos de posse de bancos comerciais e passou a envolver como contraparte uma ampla gama de ativos e atores.

Entretanto, do ponto de vista internacional, a inovação mais importante introduzida foi o estabelecimento de uma rede permanente de contratos de swaps de moeda entre o Fed e os bancos centrais dos cinco países ou regiões financeiramente mais importantes: a Europa, o Reino Unido, a Suíça, o Japão e o Canadá (BC5). Esse mecanismo atualmente não estabelece limites nem autorizações prévias para que esses cinco bancos centrais possam sacar dólares automaticamente no banco central americano, mediante o depósito de um valor equivalente na sua moeda de emissão, em conta do banco central americano.

Esse instrumento foi essencial para superar o estrangulamento enfrentado pelos bancos europeus, durante a crise de 2008, devido à exagerada exposição líquida que detinham em moeda americana, até então financiada por captações de curto prazo, que simplesmente deixaram de existir da noite para o dia. Com isso, a capacidade de resposta do sistema monetário internacional a uma crise global é atualmente muito superior à existente antes da falência do Lehman.

A Figura 2 ilustra a hierarquia do atual sistema monetário internacional. No topo da nova pirâmide está o FED (N6), que detém uma capacidade ilimitada de flexibilizar a disciplina imposta aos níveis inferiores. Imediatamente abaixo (N5), estão os bancos centrais dos cinco países (BC5) que detêm acordos permanentes de swap com o Fed, que também podem emitir moeda americana de forma autônoma, para flexibilizar os limites em dólares dos bancos sob sua supervisão. Esse privilégio, no entanto, está sujeito à existência de um contrato com a autoridade americana, que pode ser rompido unilateralmente a qualquer momento.

Em seguida, estão os bancos internacionais que podem emitir depósitos em dólares. Há, no entanto, uma diferença entre eles, que desde 2008 tem pouca relevância. Os bancos 
americanos (N4) têm relacionamento direto com o Fed. Os bancos estrangeiros que operam em dólares (N3) estão vinculados a seus respectivos bancos centrais, que desde 2008 também gozam de autonomia na emissão de moeda americana.

Nos dois pisos inferiores estão, em primeiro lugar, o euromercado (N2), que apesar de ter relacionamento indireto com o Fed, por meio dos seus bancos correspondentes em Nova Iorque, comporta-se como um conjunto de agentes não emissores. No último piso (N1), estão todos os demais agentes - ANE - de todo o mundo que operam em dólares, sejam eles públicos, privados, tesouros nacionais, bancos centrais (fora os BC5) e as agências multilaterais.

Um último comentário importante diz respeito às moedas internacionais, que não a norte-americana. Elas oferecem algumas das funções que o dólar exerce no exterior, mas foram deixadas de lado, por terem uma importância muito mais limitada geograficamente e em termos de mercado do que a detida pela moeda americana no SMI.

Figura 2

Hierarquia monetária do sistema dolarizado pós-2008

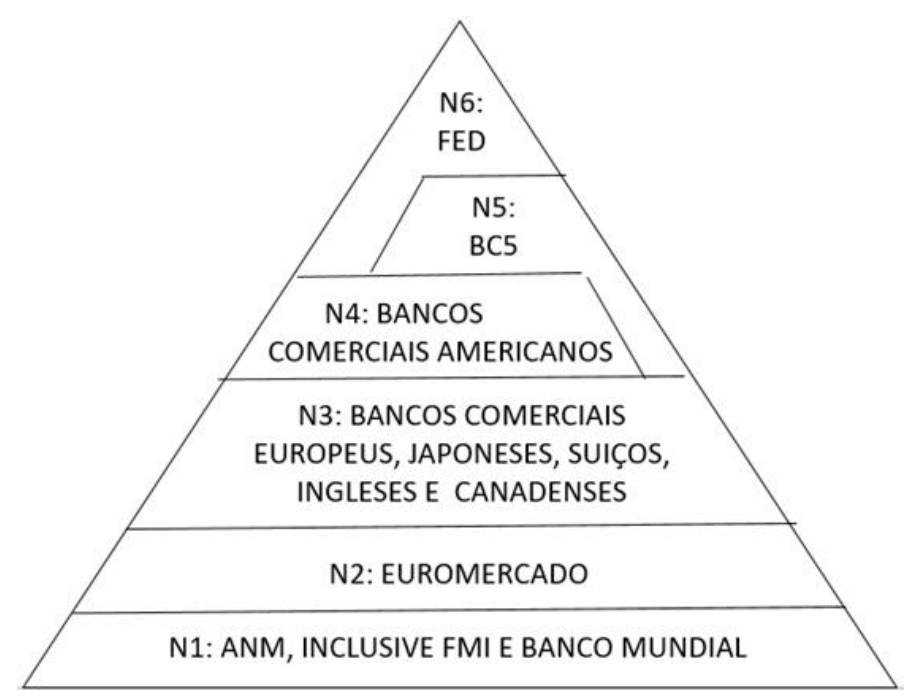

Fonte: Elaboração do autor.

\section{Conclusões}

Existe uma contribuição original de Minsky ao pensamento monetário pós-keynesiano ainda pouco conhecida: o conceito de restrição de sobrevivência. Essa survival constraint imposta pelo Estado obriga os agentes econômicos a gerir seus fluxos de caixa de modo a sempre manterem um montante da moeda, emitida pelo poder público, igual ou superior a suas obrigações de pagamento. Caso contrário, estarão sujeitos a penalidades como a falência, no caso das empresas, ou a pobreza, no caso das famílias. 
Nessa tarefa, as famílias e as empresas contam basicamente com as entradas de caixa provenientes de suas operações rotineiras. Podem ademais recorrer aos mecanismos de realocação e de flexibilização e disciplina (empréstimos e vendas de ativos), operados por mercados organizados. Na prática, graças a esses instrumentos, um grande número de unidades econômicas consegue no mundo moderno conviver com uma forte restrição de sobrevivência. A necessidade de renegociar constantemente dívidas tornou-se um fato normal. Esse comportamento gera, no entanto, um efeito adverso para a estabilidade do sistema econômico. Provoca um aumento da fragilidade financeira e, com isso, aumenta a possibilidade de que choques possam se transformar em crises financeiras.

Conforme apontado nesse trabalho, essa é a base da conhecida Hipótese da Instabilidade Financeira formulada por Minsky. Na medida em que a moeda é privada e flexível (depósitos à vista), a competição e a busca do lucro por parte dos bancos tendem, com o tempo, a provocar o relaxamento dos critérios de risco adotados na concessão de empréstimos. Com isso, torna-se cada vez mais comum a existência de unidades que convivem rotineiramente com uma forte restrição de sobrevivência - as unidades especulativas e Ponzi - em lugar das que adotam formas robustas de financiamento - as unidades hedged. Há assim, nos sistemas monetários modernos, uma inconsistência constitutiva que empurra inevitavelmente o sistema econômico em direção à instabilidade financeira.

Diante desse cenário, esse texto procurou mostrar que o instrumental minskyano pode ir mais além da Hipótese da Instabilidade financeira e ajudar a também tratar outros temas. A restrição de sobrevivência, ademais de ser uma limitação microeconômica, possui também uma dimensão macro. Os mecanismos de alocação e de flexibilidade e disciplina, como o próprio nome diz, gerenciam as opções financeiras dos agentes econômicos. Os Estados, através de seus bancos centrais - e em menor grau dos Tesouros Nacionais - são os operadores centrais da restrição de sobrevivência macroeconômica, através da fixação da taxa de juros e, portanto, da instalação ou não de uma maior disciplina sobre os mercados financeiros e de bens e serviços. Os bancos centrais também têm um papel importante para prevenir que as crises cheguem a produzir situações disfuncionais de instabilidade financeira ${ }^{16}$. As autoridades monetárias não estão sujeitas a uma restrição de sobrevivência na moeda que emitem. Entretanto, são obrigadas a respeitar as limitações que lhes são impostas por uma survival constraint na moeda internacional - o dólar.

Nesse cenário, os EUA detêm uma posição única, pela condição de emissores da moeda que comanda o sistema financeiro internacional. Diferentemente dos demais países, os americanos coletivamente não estão obrigados a respeitar uma restrição de sobrevivência de natureza externa. Não há fronteiras nacionais dentro do sistema dólar. Há apenas agentes residentes e estrangeiros, que operam no interior do seu sistema monetário.

(16) Para uma discussão dos conceitos de fragilidade e instabilidade financeira na visão minskyana, ver Burlamaqui e Torres (2020). 
A centralidade do sistema monetário americano garante aos EUA - e particularmente ao FED - um papel central na condução das crises financeiras internacionais, a exemplo do que se viu em 2008 e novamente em 2020. Nesses dois episódios, os americanos, no intuito de impedir a eclosão de uma situação de instabilidade financeira, usaram seu poder monetário para garantir o funcionamento dos mercados de liquidez e de precificação de ativos em dólar em todas as partes do mundo. Essa atitude teve como fim basicamente resguardar seu sistema financeiro nacional. Entretanto, dada a inexistência de limites entre seu sistema monetário nacional e o internacional e a relevância da sua moeda para o sistema global dolarizado, a mobilização de instrumentos do Fed transcendeu os mecanismos domésticos.

O sistema monetário e financeiro dolarizado, no formato que tinha até 2008, já era formado por um conjunto muito amplo de instituições e mercados: o sistema monetário nacional americano; os mercados offshore dolarizados; e as empresas, bancos internacionais, governos e sistemas monetários nacionais. Desde então, foram introduzidos novos mecanismos de operação que integraram de forma permanente os cinco dos principais bancos centrais estrangeiros ao sistema da reserva federal americano. Essa articulação se deu através de mecanismos de swap de moedas que dede então passaram a ser automáticos e sem qualquer limite quantitativo. Trata-se, portanto, da descentralização internacional de parte da autoridade sobre a moeda americana, de modo que esses bancos centrais estrangeiros possam em momentos de crise rapidamente irrigar de dólares seus respectivos sistemas financeiros. Essa inovação promoveu, do ponto de vista minskyano, uma mudança importante na composição da hierarquia do sistema monetário internacional.

A partir do conceito de restrição de sobrevivência, a visão minskyana amplia as possibilidades de entendimento dos sistemas monetários e financeiros, nacionais e internacional, a partir de uma perspectiva cartalista da moeda. O papel do Estado nesse cenário não se limita apenas a promover a correção de eventuais custos excessivos de transação ou de falhas de mercado, como proposto pelas teorias mainstream. O poder público deixa de ser visto como um ator externo ao mercado para se tornar o originador e o gestor central do ordenamento do sistema. Nesse contexto, os Estados operam o sistema monetário não só para promover ordem, mas também para atender a objetivos políticos. No caso dos Estados Unidos, a centralidade da sua moeda lhe confere uma condição de poder diferenciada no cenário internacional, inclusive no uso do dólar como um instrumento bilateral de coerção ${ }^{17}$. A aplicação da visão minskyana sobre a moeda se estende assim desde a Economia até a Economia Política Internacional.

\section{Bibliografia}

AGLIETTA, M. A theory of capitalist regulation: the US experience. London: Verso, 2015.

(17) O uso pelos Estados Unidos das sanções monetárias contra o Irá é um exemplo do uso poder que a hierarquia monetária internacional oferece aos americanos (Torres, 2019b). 
Ernani Teixeira Torres Filho

BELL, S. The role of the state and the hierarchy of money. Cambridge Journal of Economics, 2001

BLOCK, F. The origins of the international financial disorder. University of California Press, 1977.

BURLAMAQUI, L.; TORRES, E. The Corona crisis: mapping and managing the (western?) financial turmoil - a Minskyan approach. Rio de Janeiro: UFRJ. Instituto de Economia, 2020. (Texto para Discussão, n. 10). Disponível em: https://www.ie.ufrj.br/images/IE/TDS/2020/TD IE 010 2020 BURLAMAQUI TORRES\% 20FILHO.pdf.

DE CONTI, B.; PRATES, D.; PLIHON, D. O sistema monetário internacional e seu caráter hierarquizado. In: CINTRA, M.; MARTINS, R. (Org.). As transformações no sistema monetário internacional. IPEA, 2013.

FRIEDMAN, M. The quantity theory of money. In: WALTERS, A. (Ed.). Money and banking. Penguin, 1973.

GRAEBER, D. Debt: the first 5,000 years. Brooklyn, N.Y: Melville House, 2011.

HELLEINER, E. States and the reemergence of global finance: from Bretton Woods to global finance. Cornell University Press, 1994.

HUME, D. Of money, and other economic essays. 1777. Disponível em http://www.feedbooks.com/book/6709/of-money-and-other-economic-essays.

INGHAM, G. The nature of money. Polity Press, 2004.

KNAPP, F. State theory of money. Simon Publications Inc., 2003.

KELTON, S. The deficit mith. Public Affairs, 2020.

KEYNES, J. M. The treatise on money. Martino Mansfield Center, 2011.

KEYNES, J. M. The General Theory of employment, interest and money. London: Palgrave Macmillan, 2007.

KEYNES, J. M. The ex ante theory of interest rates. Economic Journal, p. 663-669, Dec. 1937.

KEYNES, J. M. A monetary theory of production. Der Stand und die nächste Zukunft der Konjunkturforschung: Festschrift für Arthur Spiethoff. Munich: Duncker \& Humboldt, 1933. p. 123-125. Disponível em: https://www.hetwebsite.net/het/texts/keynes/keynes1933mtp.htm.

MARTIN, Felix. Money: the unauthorised biography. The Bodley Head, 2014.

MEHRLING, P. Elasticity and discipline in the global swap. Barnard College and INET, 2015. Disponível em https://www.ineteconomics.org/uploads/papers/WP27-Mehrling.pdf. 
MEHRLING, P. The inherent hierarchy of money. In: TAYLOR, L.; REZAI, L.; MICHL, T. (Ed.). Social fairness and economics: economic essays in the spirit of Duncan Foley. Routledge, 2013. p. 394-404.

MEHRLING, P. The new Lombard Street: how the fed became the dealer of last resort. Princeton, NJ: Princeton Univ. Press, 2011.

MEHRLING, P. The vision of Hyman P. Minsky. Journal of Economic Behavior \& Organization, v. 39, p. 129-158, 1999.

MINSKY, H. The financial instability hypothesis. New York: The New Economics Institute, 1992. (Working Paper, 74). Disponível em: http://www.levy.org.

MINSKY, H. Stabilizing an unstable economy. Yale University Press, 1986a.

MINSKY, H. Global consequences of financial deregulation Hyman P. Minsky Archive. 1986b. Disponível em: https://digitalcommons.bard.edu/hm_archive/378.

MINSKY, H. Financial intermediation in the money and capital markets. In: PONTECORVO, G.; SHAY, R. P.; HART, A. G. (Ed.). Issues in banking and monetary analysis. New York: Holt, Rinehart and Winston, 1967. p. 33-56.

MINSKY, H.; PAPADIMITRIOU, D. Induced investment and business cycle. Elgar Pub, 2004.

NIELSON, D. Minsky, key contemporary thinkers. Polity Press, 2019.

ROCKOFF, H. Adam Smith on money, banking and the price level. In: BERRY, C. J.; PAGANELLI, M. P.; SMITH, C. The handbook of Adam Smith. Oxford University Press, 2013.

SMITH, A. An inquiry into the nature and causes of the wealth of nations. Metalibri, 2007.

STIGUM, M.; CRESCENZI. A. Stigum's money market. $4^{\text {th }}$ ed. New York: McGraw-Hill, 2007.

TOOZE, A. Crashed: how a decade of financial crises changed the world. Kindle Edition, 2018.

TORRES, E. A crise do sistema financeiro globalizado contemporâneo. Revista de Economia Política, v. 34, n. 3 (136), p. 433-450, jul./set. 2014.

TORRES, E. Dolarização e crise no Equador a partir da hierarquia monetária minskyana. Revista Oikos, v. 18, n. 3, p. 24-40, 2019a. Disponível em: http://www.revistaoikos.org/seer/index.php/oikos/article/viewArticle/599.

TORRES, E. A bomba dólar: paz, moeda e coerção. Rio de Janeiro: UFRJ. Instituto de Economia, 2019b. (Texto para Discussão, n. 26). Disponível em: https://www.ie.ufrj.br/images/IE/TDS/2019/TD_IE_026_2019_TORRES\%20FILHO.pdf. 
TORRES, E.; MARTINS, N. Regulação financeira em Minsky: restrição de sobrevivência, instabilidade financeira e regulação dinâmica. Rio de Janeiro: UFRJ. Instituto de Economia, 2020. (Texto para Discussão, n. 4). Disponível em: https://www.researchgate.net/publication/342747306_Regulacao_Financeira_em_Minsky_Re stricao_de_Sobrevivencia_Instabilidade_Financeira_e_Regulacao_Dinamica.

WRAY, L. Minsky crisis. Levy Economics Institute of Bard College, Mar. 2011. (Working Paper, n. 659).

WRAY, L. Why Minsky matters: an introduction to the work of a maverick economist. Princeton University Press, 2016. 